\title{
A BIOPOLIITICA DE MICHEL FOUCAULT: controle do indivíduo e da sociedade
}

\section{MICHEL FOUCAULT'S BIOPOLICY: control of the individual and society}

\author{
Yossonale Viana Alves ${ }^{1}$ \\ PPGEP/IFRN: https://orcid.org/0000-0003-0206-8642 \\ Marcio Adriano de Azevedo ${ }^{2}$ \\ PPGEP/IFRN: http://orcid.org/0000-0003-1964-786X
}

DOI: $10.21680 / 1982-1662.2021 v 4 n 30 I D 19998$

\section{Resumo}

Este trabalho de cunho bibliográfico objetivo apreender a concepção de biopolítica desenvolvida por Michel Foucault, tendo como referente uma análise bibliográfica de suas obras. Esse pensador oferece um arcabouço literário para analisar a evolução histórica das sociedades contemporâneas de modernização econômica e social capitalista, tendo como objeto a imersão na racionalização econômica dos processos relacionados à vida humana. Entende que a vida humana não apenas passou a ser parte integrante das decisões políticas, dos cálculos de poder, e da própria racionalização social como um todo. Para ele a vida é gerida, controlada e formatada com base na maximização de sua utilidade. Sendo assim, o controle da sociedade sobre os indivíduos não se efetua apenas pela consciência ou pela ideologia, mas no corpo e com o corpo, utilizando-se os procedimentos de poder postos em prática pelo Estado moderno que tem como tarefa principal a configuração e o controle do indivíduo e da própria sociedade, seja na educação, seja nas relações de trabalho. Considera-se, por fim, nesse ensaio, a necessidade do exercício reflexivo para se

\footnotetext{
${ }^{1}$ E-mail: sonalealves@hotmail.com

2 E-mail: marcio.azevedo@ifrn.edu.br
} 
compreender o controle do indivíduo e da sociedade, imersos em um mundo no qual a biopolítica pode ser entendida como regulamentadora da vida.

Palavras-chave: Biopolítica. Estado. Discurso. Controle.

\begin{abstract}
:
This bibliographic work aims to apprehend the concept of biopolitics developed by Michel Foucault, having as reference a bibliographic analysis of his works. This thinker offers a literary framework to analyze the historical evolution of contemporary societies of capitalist economic and social modernization, having as object the immersion in the economic rationalization of the processes related to human life. He believes that human life has not only become an integral part of political decisions, of calculations of power, and of social rationalization itself as a whole. For him, life is managed, controlled and shaped based on maximizing its usefulness. Thus, the control of society over individuals is not affected only by conscience or ideology, but in the body and with the body, using the procedures of power put into practice by the modern State whose main task is the configuration and the control of the individual and of society itself, whether in education or in labor relations. Finally, in this essay, the need for reflective exercise to understand the control of the individual and society, immersed in a world in which biopolitics can be understood as regulating life, is considered.
\end{abstract}

Keywords: Biopolitics. State. Speech. Control. 
Introdução

0 trabalho de Foucault é reencenar com as grandes obras que mudaram para nós o que significa pensar ${ }^{3}$. (DELEUZE, 1986, p. 128, tradução nossa).

A epígrafe evidencia que Foucault se tornou um teórico inevitável para pensar sobre alguns mecanismos e sociabilidades modernos, sem citar que sua contemporaneidade tem relação direta com sua forma de fazer perguntas, de refletir para além do âmbito clássico da filosofia e das ciências sociais, de reintroduzir problemas atuais em uma perspectiva histórica mais ampla. É um pensador atual porque os problemas que propõe são muito mais complexos, e essa complexidade é o que nos permite compreender os mecanismos de controle das sociedades modernas.

Este trabalho objetiva apreender a concepção de biopolítica desenvolvida por Michel Foucault, tendo como referente uma análise bibliográfica de suas obras. Um exercício de olhar para se compreender o controle do indivíduo e da sociedade imersos em um mundo no qual a biopolítica pode ser entendida como regulamentadora da vida.

Foucault foi um filósofo, historiador das ideias, teórico social, filólogo, crítico literário e professor da cátedra História dos Sistemas do Pensamento, no célebre Collège de France, de 1970 até 1984; um pensador de nosso tempo e momento histórico social. Suas teorias abordam a relação entre poder e conhecimento e como esses são usados como uma forma de controle social por meio de instituições sociais. Embora, muitas vezes, seja citado como um pós-estruturalista e pós-modernista, Foucault acabou rejeitando esses rótulos, preferindo classificar seu pensamento como uma história crítica da modernidade, na qual a vida humana tem lugar de destaque. Seu pensamento foi e é muito influente tanto para grupos acadêmicos, quanto para ativistas sociais. (ARAUJO, 2017).

Foucault nos mostra por meio do conjunto de sua obra um arcabouço bibliográfico para sopesar a evolução histórica das sociedades contemporâneas de modernização econômica e social capitalista. Sua ênfase de investigação tem como foco a crescente racionalização econômica dos processos relacionados à vida humana imbrincados em questões que envolvem saber e poder. Assim, ele projeta que a vida

\footnotetext{
3 “L'ouvre de Foucault se ré-encheine avec les grandes ouvres qui ont changé por nous ces que signifie penser".
} 
humana não apenas passou a integrar as decisões políticas, dos cálculos de poder, mas também da própria racionalização social como um todo: a vida é gerida, controlada e configurada por um delineamento se conforma na maximização de sua utilidade. Para ele, o controle da sociedade sobre os indivíduos não se efetua apenas pela consciência ou pela ideologia, mas no corpo e com o corpo. Adverte que os procedimentos de poder postos pelo Estado moderno dispõem como tarefa principal a configuração e o controle do indivíduo e da própria sociedade, portanto, da vida.

A forma de análise, elaborada pelas investigações desenvolvidas por Foucault, revela um importante nível de funcionamento das relações políticas nas sociedades contemporâneas, posto que suas pesquisas genealógicas proporcionam avaliar os aspectos desumanizadores da sociedade técnico-científica que foi se tecendo ao longo da história.

Assim, a mudança nas relações de forças que dão ensejo à entrada da vida nos mecanismos da produção trará toda uma preocupação com a higiene e com a performance do corpo mediante o jogo duplo de um poder ao mesmo tempo: individualizante e totalizante, corpo do indivíduo e corpo da população. Além disso, Foucault ressalta que:

[...] o problema não é de constituir uma teoria do poder que teria como função refazer o que um Boulainvilliers ou Rousseau queriam fazer. Todos os dois partem de um estágio originário em que todos os homens são iguais, e depois o que acontece? Invasão histórica para um, acontecimento mítico para outro, mas sempre aparece a idéia de que, a partir de um momento, as pessoas não tiveram mais direitos e surgiu o poder. Se o objetivo for construir uma teoria do poder, haverá sempre a necessidade de considerá-lo como algo que surgiu em um determinado momento, de que se deveria fazer a gênese e depois a dedução. Mas se o poder na realidade é um feixe aberto, mais ou menos coordenado (e sem dúvida mal coordenado) de relações, então o único problema é munir-se de princípios de análise que permitam uma analítica do poder. (FOUCAULT, 1979, p. 154).

A par disso, e tendo como ponto de partida o olhar crítico de Foucault, busca-se analisar as proposições para se interpretar a vida em sociedade desse pensador por meio do universo de suas obras para, em seguida, apreender a concepção de biopolítica desenvolvida por ele. Observa-se, de antemão, que essa foi se constituindo tendo como princípios de análise o controle do indivíduo e da sociedade. Todavia, para albergar o pensamento desse teórico sobre a temática específica desse trabalho, é preciso, primeiro, embarcar no universo de suas obras. 
É consenso entre os intérpretes da obra de Foucault que essa está dividida em três fases distintas: arqueológica, genealógica e ética. A primeira fase, conhecida como período da "arqueologia", é voltada, sobretudo, para questões relativas à constituição dos saberes. O segundo momento, conhecido como período da "genealogia", é centrado sobre questões relativas aos mecanismos do poder. 0 terceiro momento trata de questões relativas à constituição do sujeito ético. 0 Quadro 01 traz a exposição dos três domínios de Foucault em suas fases de produção acadêmico-científica e os livros publicados:

Quadro 01: Os três domínios de Foucault (1961-1984)

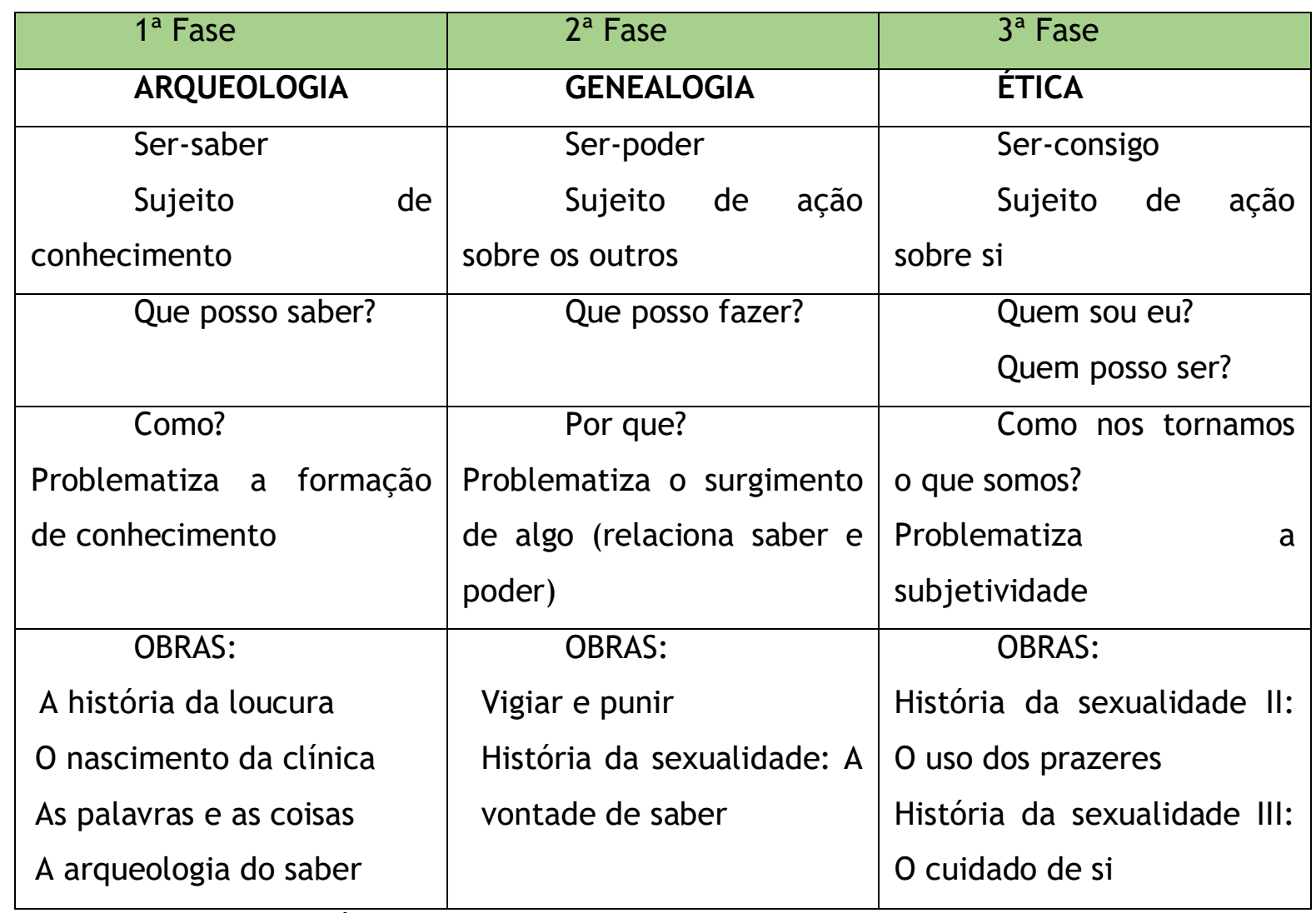

Fonte: Elaboração própria (2019).

A construção conceitual da concepção de biopolítica aparece para Foucault, pela primeira vez, em seu curso: "Em Defesa da Sociedade" e a publicação do primeiro volume de "História da Sexualidade". Mas, é apenas com "Segurança, Território e População" e posteriormente em o "Nascimento da Biopolítica" que o tema se desenvolve por completo. Para Castro (2011), por biopolítica Foucault busca compreender como o poder se desenvolve e calha a conduzir a vida das pessoas.

Dito isto, a concepção de biopolítica configura-se em meio a questões de poder, 
de controle do indivíduo e da sociedade. Este estudo é conduzido, sobretudo, à fase genealógica de Foucault. Para isso, foi estruturado em duas sessões: na primeira, a genealogia do poder em Foucault e, na segunda, a biopolítica como controle do indivíduo e da sociedade que nesse ensaio serão discutidas com estudiosos da obra de Foucault, fazendo-se inflexões argumentativas sobre a escola como instituição educativa e as relações de trabalho no mundo atual, as quais corroboram as reflexões dos autores sobre a biopolítica em Foucault.

\section{A genealogia do poder em Foucault}

Considera-se que Foucault não tem uma teoria geral do poder, podendo essa ser aplicada a todas as relações de poder existentes em sociedade, em qualquer contexto. Ele não pretendia fundar uma teoria geral e globalizante, mas trabalhar uma analítica de poder capaz de dar conta do seu funcionamento local, em campos e discursos específicos e em épocas determinadas, nesse sentido, pode-se afirmar que ele não desprezava em suas análises a história - como eixo estruturador do conhecimento. Como ele destaca: "o que está em jogo nas investigações que virão a seguir é dirigirmos menos para uma 'teoria' do poder que para uma 'analítica' do poder: para uma definição do domínio específico formado pelas relações de poder e determinação dos instrumentos que permitam analisá-lo" (FOUCAULT, 1979, p. 80).

O filósofo francês aponta historicamente que nas sociedades antigas, précapitalistas, o poder era visto como um direito supremo. 0 soberano era aquele cujo poder residia essencialmente no direito sobre a vida e a morte dos homens. A fim de assegurar a defesa absoluta de sua pessoa ou território, era-lhe permitido fazer apreensão das coisas, do tempo, dos corpos, valer-se de seus súditos, e finalmente da vida. Estava mais ao seu alcance aplicar castigos a infratores, punindo-os com a execução. Contudo, se o direito do soberano sobre a morte dos súditos é imediato, seu poder sobre a vida não. Quando age sobre esta é porque the é lícito matar ou deixar de fazê-lo. (FOUCAULT, 2009).

No entanto, segundo Foucault, a partir XVIII vê-se nascer uma nova organização do poder. 0 direito de morte tendia a se deslocar ou, pelo menos, a se apoiar nas exigências de um poder que gerasse a vida e a ordenasse em função dos seus reclames. 0 poder político passou a assumir os contornos de um biopoder, um poder 
que se exerce sobre a vida "que compreende sua gestão, sua majoração, sua multiplicação, o exercício sobre ela, de controles precisos e regulações de conjunto" (FOUCAULT, 2009, p. 148). Se antes vigorou o princípio de que era legítimo provocar a morte ou deixar viver, agora, invertendo-se a esta equação, os mecanismos de poder visam produzir a vida, articulados à possibilidade de se deixar morrer. Trata-se do "poder de causar a vida ou devolver à morte", ou seja, "um poder destinado a produzir forças, a fazê-las crescer e a ordená-las mais do que a barrá-las, dobrá-las ou destruí-las" (FOUCAULT, 2009, p. 150).

Frise-se que é esse poder que Foucault denomina biopolítica, a qual representa uma estratégia ao mesmo tempo de proteção e de maximização da força representada pela vida dos indivíduos, vida que passa a valer muito, “não em nome de uma pretensa filantropia, mas porque ela é essencialmente força de trabalho, isto é, produção de valor." (REVEL, 2006, p. 55). Nesse argumento, a vida "só é útil porque é, ao mesmo tempo, sã e dócil, ou seja, medicalizada e disciplinarizada” (REVEL, 2006, p. 56).

Desta feita, com esta administração da vida, a modernidade alcançou seu sentido biológico. A espécie humana, enquanto espécie biológica passou a fazer parte das estratégias políticas. Foucault redescobre, no bios, a matéria-prima das lutas políticas e das afirmações de direitos da modernidade. Além disso, afirmou que "as disciplinas do corpo e as regulações da população constituem os dois polos em torno dos quais se desenvolveu a organização do poder sobre a vida" e se encontram “interligados por todo um feixe intermediário de relações” (FOUCAULT, 2012, p. 151 152) estabelece, assim, a noção de complementaridade do poder soberano pelo biopoder na medida em que identifica que o segundo foi indispensável ao desenvolvimento do capitalismo.

Para o autor, o sistema capitalista pressupunha a inserção controlada dos corpos no aparelho de produção (disciplina), mas também um ajustamento dos fenômenos de população aos processos econômicos. Ressalta que para além da docilidade dos corpos, o capitalismo também exigiu métodos de poder capazes de majorar forças e aptidões em geral. Afinal, o poder de soberania se mostrou incapaz de “organizar o corpo econômico e político num contexto marcado pela explosão demográfica e crescente industrialização." (AYUB, 2014, p. 60).

Nesse seguimento, o biopoder, com “suas formas e procedimentos múltiplos”, é que propiciou o ajuste "da acumulação dos homens à do capital, a articulação do 
crescimento dos grupos humanos à expansão das forças produtivas e a repartição diferencial do lucro". (FOUCAULT, 2012, p. 153-154). Na visão de Castro (2011) é, justamente, nessa esfera que a biopolítica não se apropria da vida para suprimi-la, mas sim para administrá-la em termos regulativos, ou seja, trata-se de distribuir o vivente em um domínio de valor e de utilidade. É, portanto, nesse movimento que Foucault evidencia como a potência da vida humana passa a ser aproveitada pelo Estado e pelas instituições como elemento de poder, ou seja, passa-se a incluir a vida humana nos cálculos do poder. A lógica do biopoder é justamente maximizar a vida humana para que ela seja produtiva.

Esposito (2010) adota o pensamento de que a biopolítica se encontra em uma perspectiva oposta ao poder soberano e aduz que se este "se exercia em termos de subtração, de tributação - dos bens, dos serviços, do sangue - dos próprios súbditos”, aquela, pelo contrário, volta-se "para a vida deles não só no sentido da sua defesa, mas também no do seu desenvolvimento, da sua potenciação, da sua maximização." Então, se o poder soberano “tolhia, refreava, até aniquilar”, a biopolítica “solda, aumenta, estimula" a vida em sua dimensão utilitária (ESPOSITO, 2010, p. 60-61).

Para Bert (2013) “a disciplina consolida a biopolítica que, em troca, embasa o eixo das técnicas disciplinares e suas tentativas de majoração coextensiva das forças e da obediência de um indivíduo." (BERT, 2013, p. 128); ou seja, o poder disciplinar e a biopolítica articulam-se formando um sistema de aparatos que se auto-fortalecem. Significa dizer que os dispositivos disciplinares e biopolíticas se conjugam nas novas técnicas políticas que se fazem necessárias para o governo das massas urbanas multifacetadas, ajustando-as à dinâmica da produção e do consumo em ascensão na sociedade capitalista.

Foucault (1987) identifica, assim, o momento a partir do qual o biológico passa a se refletir no político, fazendo com que o fato de viver incida no campo de controle do saber e, de forma reflexa, de intervenção do poder. Igualmente, a conexão entre a biopolítica e o capitalismo evidencia-se por meio de controles diversos sobre a vida (demografia, higiene pública, projetos de urbanismo, etc.) transformando os indivíduos em população, ou seja, produz-se um grande e produtivo corpo mecânico que une forças para além de si.

Com efeito, Foucault elaborou o conceito de biopoder para designar o poder de administrar, controlar e conformar as populações (nisso estavam compreendidos a 
educação, a assistência, a saúde, os transportes, a securitização de diversos aspectos da vida social etc.), posto em funcionamento, sobretudo, em paralelo à emergência do Estado de bem-estar social.

A perspectiva analítica do poder vai impor também um deslocamento sensível em relação às análises tradicionais sobre esta noção no que concerne ao papel do Estado. Ora, para Foucault, "uma sociedade sem relações de poder somente pode ser uma abstração" (FOUCAULT, 1982, p. 222). Isso implica que qualquer agrupamento humano vai estar sempre permeado por relações de poder, posto que a existência deste tipo de relação é coexistente à vida social. Neste sentido, o Estado parece perder certo privilégio que a análise política lhe tem garantido, na medida em que a instituição estatal vai ter seu papel redimensionado. 0 Estado não detém a prerrogativa de ser o centro constituidor das relações de poder e, a partir da consolidação do Estado Pátrio, há uma captura de focos de poder. Ademais:

[...] é certo que nas sociedades contemporâneas o Estado não é simplesmente uma das formas especificas de exercício do poder mesmo se for a mais importante - mas, de um certo modo, todas as formas de relações de poder devem a ele se referir. Todavia isto não se dá porque elas se derivam do Estado; mas porque as relações de poder vêm sendo paulatinamente colocadas sob o controle do Estado. (FOUCAULT, 1982, p. 224).

Ao lado desse deslocamento da análise tradicional é estabelecido também um dos princípios da analítica do poder: “o poder é um feixe de relações mais ou menos piramidalizado, mais ou menos coordenado" (FOUCAULT, 1979, p. 248). Resultado, essa assertiva conduz a uma forma diferente de perceber o poder, pois através desse modelo abre-se a possibilidade de compreender com mais afinco a dinâmica, fragmentada, móvel e, ainda contraditória, do poder em funcionamento na sociedade.

Enfim, nessa primeira parte, se destacou algumas das concepções de Foucault a respeito do poder. Certamente um assunto como este poderia ser tratado de forma mais detalhada e exaustiva. Aqui foi merecedor apenas de uma primeira abordagem. Na segunda parte deste artigo o enfoque será a biopolítica como forma de controle do indivíduo e da sociedade, relacionando-a com as questões de governamentabilidade e do discurso instrumentado, sem mencionar a pérfida sensação de liberdade das pessoas. 


\section{Biopolítica: controle do indivíduo e da sociedade}

Para descrever as grandes transformações das sociedades ocidentais a partir do século XVII e o desenvolvimento de duas novas formas de poder que concerniam tanto aos indivíduos quanto às coletividades, Foucault acena que: de um lado, o poder totalizante, o qual cria aparatos estatais capazes de governar populações, levando a um processo crescente de massificação e burocratização da sociedade; de outro, complementar a esse poder, encontram-se as técnicas individualizantes, consistentes em saberes e práticas destinados a dirigirem os sujeitos de modo permanente e detalhado.

Hardt e Negri (2004) consideram que a obra de Foucault permite reconhecer uma transição histórica e de época das formas sociais da sociedade disciplinar para a sociedade de controle. A sociedade disciplinar é aquela na qual o comando social é construído mediante uma rede dispersa de dispositivos que produzem e regulam os costumes, os hábitos e as práticas produtivas. Por meio de instituições disciplinares (prisão, fábrica, hospital, escola, universidade) que fornecem explicações lógicas para a razão da disciplina, essa sociedade põe para funcionar mecanismos de inclusão e de exclusão. A sociedade de controle desenvolve mecanismos cada vez mais democráticos, distribuídos pelos corpos (em sistemas de bem-estar, atividades monitoradas) e cérebros (em sistemas de comunicação, redes de informação) dos cidadãos. Essa sociedade pode ser caracterizada pela intensificação e síntese dos aparelhos de normalização e de disciplinarização.

Foucault (2003) avalia o poder como algo que além de opressor também é criador de saberes e verdades, e onipresente no sujeito. É a imposição de uma vontade sobre terceiros, que não caracteriza uma posse, mas uma prática social interpessoal. E o que se segue a isso é a criação da verdade, pois ele apresenta as particularidades do meio social onde se originou. Defende a tese de que a verdade é mutável e altera-se de acordo com as circunstâncias, tais como o espaço e o tempo, sendo gerada por um fenômeno denominado poder. Afirma ainda que, não é possível haver verdade sem poder, pois ambos são conceitos intrínsecos. 0 poder seria aquele que gera o saber, o conjunto de conhecimentos e crenças que caracteriza a verdade. 0 poder, enquanto produz, organiza, e enquanto organiza, fala e se expressa como 
autoridade. A linguagem, à medida que comunica, produz mercadorias, mas, além disso, cria subjetividades, põe umas em relação às outras e as ordena. (FOUCAULT, 2003).

Desse modo, pode-se fazer sentir, desde já, o lugar a ser atribuído às relações de saber-poder, como a sua dita conexão com a verdade, sem aludir suas relações com o conhecimento, discurso, direito e governamentabilidade.

Posto isso, é imprescindível citar o peso que suas ideias tiveram para a pósmodernidade, maiormente no contexto do fim das visões de mundo totalizantes e da fragmentação do poder.

\section{Conhecimento, Poder, Discurso e Verdade}

Nos anos de 1980, Foucault inicia uma nova linha de investigação: os atos que o sujeito pode e deve operar livremente em si para chegar à verdade. Este novo eixo é chamado de regime de verdade. Seu pensamento acredita-se, visava ligar em conjunto três dimensões para apreensão da realidade: o conhecimento, o poder e o discurso.

Foucault (2004) pesquisou sobre a figura do sujeito de conhecimento ao se contrapor a certa noção de conhecimento proveniente do marxismo acadêmico. Esta noção marxista, segundo o autor, estaria implicando formas de conhecimento prévias ao sujeito humano, ao estabelecer uma relação entre as condições econômicas, sociais e políticas que iriam apenas se imprimir neste sujeito de conhecimento dado. Nessa perspectiva, o filósofo propõe fazer uma história do sujeito do conhecimento. Alega que a verdade tem uma história específica. A verdade, portanto, foi interrogada em sua historicidade e na sua forma de manifestação em um dado contexto de práticas sociais que engendram domínios de saber, visto que ela não é natural, tampouco dada pela natureza humana.

Foucault (2004) também assinala como diversos discursos se fundamentam na formulação de um discurso verdadeiro, fruto de nossa vontade histórica da verdade: as práticas econômicas, a moral, a literatura, a palavra da lei, teorias da riqueza e do direito; todos esses discursos se pautaram em saberes exteriores da sociologia, psicologia, psiquiatria ou medicina para se legitimarem enquanto discursos de verdade, esquecendo-se da provisoriedade dessa.

Em A ordem do discurso esse teórico questiona as peripécias da vontade da 
verdade: a vontade da verdade se mascara em seu próprio funcionamento, no seu “desenrolar necessário” na relação complexa da verdade com a sua vontade (FOUCAULT, 1996, p. 20). O discurso do verdadeiro, assim, cria a aparência de libertar o sujeito do poder, do desejo e da violência. Mas, neste processo, o próprio discurso do verdadeiro não consegue reconhecer a sua vontade constitutiva (o poder, o desejo, a violência) que o atravessa. O discurso do verdadeiro tenta apagar o seu próprio componente discursivo, numa espécie de denegação de si, pois tenta a todo custo ocupar, como bem define Foucault (1996), o menor espaço possível entre o pensamento e a palavra; visa, assim, tornar-se transparente, num desdobramento espontâneo entre as formas da língua e os efeitos de sentido.

Para enunciar dentro do discurso verdadeiro não basta tão somente enunciar verdades, é preciso, sobretudo, obedecer a uma “polícia discursiva”. (FOUCAULT, 1996, p. 37). Como explanou Foucault, um enunciado só ganha o estatuto de verdadeiro em uma disciplina se preencher um todo complexo em um jogo de regras, definições, instrumentos, e se ater a um plano determinado de objetos passíveis de serem conhecidos. A construção de uma verdade científica também exige o erro em sua função positiva. Ele nos alerta para duvidar dos incidentes da verdade ao apontar que a sua própria vontade se dá a partir de relações de poder.

Em síntese, a verdade é produzida e influenciada pelo poder, assim como sofre alteração dependendo do tempo e espaço. Nas palavras do autor:

Há um combate "pela verdade" ou, o menos, "em torno da verdade" entendendo-se mais uma vez, que por verdade não quero dizer "o conjunto das regras segundo as quais se distingue o verdadeiro e o falso e se atribui ao verdadeiro efeitos específicos de poder"; entendendo-se também que não se trata de um combate "em favor" da verdade, mas em torno do estatuto da verdade e do papel econômico-político que ela desempenha. (FOUCAULT, 2008, p. 13, grifos do autor).

Compreende-se a partir daí o nascimento dos discursos persuasivos dos governantes, com o claro intuito de influenciar os sujeitos para acatar os objetivos do governo, seja na área econômica, financeira, ou em diversos outros assuntos. Isto promove um potencial produtivo de técnicas de persuasão, de formação de consciência e de indução de vontades. Assim, são utilizadas táticas e estratégicas para se governar a vontade dos outros. Produz-se verdades, através dos discursos, e com isso, estas verdades influem na subjetividade do sujeito, uma vez que a verdade é 
aquilo que aceitamos como verdadeiro. Isso, de algum modo, parece realidade ou é mera coincidência?

É por isto que o discurso, assim concebido, “[...] aparece como um bem - finito, limitado, desejável, útil - que tem suas regras de aparecimento e também suas condições de apropriação e de utilização; um bem que coloca [...] a questão do poder, um bem que é, por natureza, o objeto de uma luta, e de uma luta política" (FOUCAULT, 1995, p. 139).

Verifica-se, na obra de Foucault, uma crítica de como ao longo da história a vontade das pessoas foi guiada, dirigida, persuadida pela vontade do governante: como é possível dirigir a vontade das pessoas? Como na história essa vontade foi dirigida? Assim como, o que é necessário e/ou o que foi feito, para tentar se sair deste estado de sujeição? São questões apenas para reflexão, pois é necessário um trabalho intenso para compreender a forma pela qual se estruturam as relações sociais, em especial as relações de obediência e dominação que justificam a autoridade e a natureza das obrigações políticas, descrevendo os discursos que constituem a prática política e o tipo de sociedade produzido nos diferentes sistemas de formação dos discursos, tendo em vista que os dispositivos de informação/comunicação trabalham para ter o controle sobre o discurso pronunciado, atuando nos processos de identificação dos sujeitos de uma sociedade.

Frise-se que os meios de comunicação sociais, em todos os seus segmentos (formal, informal, televisivo, digital, eletrônico, etc.), participam da construção política dos países, promovendo a correlação entre o discurso da população e o discurso dos governos. Assim, os discursos veiculados, sustentados, descartados, ou mesmo silenciados pela mídia, constituem o arquivo que define, nos moldes de Foucault (1995), o sistema de enunciabilidade ${ }^{4}$, de formação e transformação dos enunciados, bem como a lei do que pode ser dito.

Foucault (2000) assevera que a sociedade de controle começa a se desenhar no século XVIII, com o aparecimento de um poder que é ao mesmo tempo disciplinador e normalizador e não se exerce mais sobre os corpos individualizados, mas se concentra na figura do Estado, em que ele é exercido com pretensões de administrar a vida e o corpo da população.

Em Foucault não existe sujeito fora do discurso: "dado que cada um de nós

\footnotetext{
${ }^{4}$ É o sistema geral da formação e da transformação dos enunciados.
} 
nasce num mundo [...] em que os discursos já estão há muito tempo circulando, nós nos tornamos sujeitos derivados desses discursos" (VEIGA-NETO, 2011, p. 91). Em outras palavras, Foucault exibe que o poder está arraigado no discurso, seja ele econômico, científico ou educacional.

0 pensamento transversal de Foucault alcançou diversas áreas, mas para o campo da Educação e do Trabalho, suas observações foram mais além. À vista disso, merece exame de como alguns enunciados conferem forma de existência aos discursos e/ou plataformas políticas, sobretudo, as questões voltadas para o campo da educação e do trabalho. Diz-se isso, porque os discursos nessas áreas se sustentam profundamente nas concepções sobre o controle da sociedade e do indivíduo.

Foucault (1986) sublinha que o controle das instituições educativas sobre os corpos e as posturas comportamentais de alunos e professores nos espaços escolares, são, sim, instrumentos de controle e poder concretizados nos elementos formadores dos discursos. Ele apresenta a disciplina como uma "fábrica de corpos submissos [...], corpos dóceis" (FOUCAULT, 1986, p. 127), dissociando, pelo discurso, o poder do corpo.

Para Foucault (2004), a escola exerce sua função de forma egocêntrica, pois só se muda a fachada, porém seus principais objetivos continuam os mesmos, independentes da época a ser vivida, desde sua institucionalização. Um exemplo claro é que cada vez mais brotam inovações pedagógicas, onde os sujeitos que sofrem a ação serão sempre os alunos e não quem pensa e efetiva esses ideais. Ele ilustra: "[...] essa vontade de verdade, como os outros sistemas de exclusão, apoia-se sobre um suporte institucional: é ao mesmo tempo reforçada e reconduzida por todo um compacto conjunto de práticas como a pedagogia [...] o saber é aplicado em uma sociedade, como é valorizado e distribuído, repartindo e de certo modo atribuído. (FOUCAULT, 2004, p.17).

Isto é, promove-se uma exterioridade para confirmar os princípios educativos postos, de forma intencional, que se utilizam da teoria e da prática apresentada nas escolas para a construção de um sujeito que não ultrapasse os muros das instituições escolares, pois o habitual da escola tende a ser inacessível às desigualdades e resistente às variações de constituição do conhecimento.

Dentro dessa lógica, a escola como organização classificatória e excludente fortalece as bases desvirtuadas de poder. Na visão de Foucault, o poder, não se 
explica pela sua função repressiva, pois o seu objetivo não é tornar os homens improdutivos, e sim controlá-los para que possam alcançar o máximo desenvolvimento de suas potencialidades, para que se thes aumente a utilidade econômica, evitando os inconvenientes da insurreição. Enfatize-se, assim, a mais sutil forma de poder/controle, que consiste na adoção de discursos repletos de persuasão, resultando na gradativa adoção pelas pessoas ou grupos como se fossem próprios. (FOUCAULT, 1979).

A característica marcante desse poder é sua invisibilidade, a falta de consciência de sua existência, tanto por parte daqueles que o exercem como daqueles que se sujeitam. Os poderes coercivos e compensatórios são visíveis e diretos. Seus elementos são calculados e objetivamente considerados. 0 poder condicionado é transparente e subjetivo. Toma-se parte da natureza das pessoas, grupos e instituições.

Diante disso, vê-se que a educação desde o seu aparecimento esteve atrelada a existência humana e a diversos interesses, sociais, políticos, culturais, notadamente religiosos. Nesse sentido, a cada década tem-se um discurso seja ele: da pobreza das crianças, jovens e adultos, das camadas desfavorecidas; da enorme desigualdade na distribuição da renda e imensas deficiências no sistema educacional; do analfabetismo; da baixa qualidade do ensino básico; da evasão e repetência no ensino; da incompleta formação docente; da péssima qualidade das escolas; do desinteresse dos alunos, etc. Todo este discurso para direcionar projetos, decretos, portarias, reformas, regulamentações, leis, enfim, diretrizes que nunca se articularam com o princípio educativo de verdade.

Candeias (1998) adverte que “afinal, não era a 'escola para todos' uma reivindicação de todos, e, sobretudo daqueles que designamos como povo, ou seja, aqueles que agrupamos de uma forma geral nos lugares mais baixos da hierarquia social”, que deveria nortear os discursos e ações políticas no país. (CANDEIAS, 1998, p. 138).

Foucault (1979) aduz que “em si mesmas as regras são vazias, violento, [...] elas são feitas para servir a isto ou aquilo, elas podem ser burladas ao saber da vontade de uns ou de outros". (FOUCAULT, 1979, p. 25). Em síntese, a educação brasileira torna-se simbólico por falta de essência, pois nem tudo nos é explicado, porém só as regras de conhecimento e a partir desse pressuposto somos sujeitados aos 
discursos orquestrados.

Apesar disso, nos instiga a repensar a educação, ou seja, a tornar o pensamento, mais uma vez possível em educação. A partir de sua perspectiva, pode-se traçar um novo modo de investigação e desenvolver novas práticas educativas. Para que isso ocorra, é necessário que antes se faça a distinção entre as possibilidades que Foucault nos propõe e as usuais formas de se pensar a educação. Essas últimas se dividem em duas posturas: a primeira é a das certezas prontas dos dogmas, que creem numa verdade revelada; a segunda é a das certezas prontas das novidades, que vão assumir antigos dogmas, tornando-se ela mesma um novo dogma. Investir numa perspectiva de se pensar a educação seria investir numa possibilidade de se escapar dessas posturas dogmáticas e tornar o pensamento possível.

Já a arena da categoria trabalho, por meio da biopolítica e dos discursos manipulados, passa a absorver dimensões precarizantes, na medida em que se coaduna com a assimilação e com a legitimação da fragilidade dos vínculos mediante a adoção de medidas como as contratualizações fragilmente reguladas, e pouco protetivas dispensadas ao trabalhador. Esse último assimilado como um recurso humano. Isto é, como um indivíduo capitalizado, cujo valor se consolida justamente pelo sobreposto capital-trabalhador, como articulado na teoria do capital humano ${ }^{5}$.

Thébaud-Mony e Druck (2007) em estudo sobre a terceirização/subcontratação no Brasil e na França apontam que este "é um fenômeno velho e novo, velho porque a subcontratação é uma prática que historicamente se faz presente desde as fases iniciais de consolidação do modo de produção capitalista, vide o putting out system ${ }^{6}$ e novo porque acaba incitando a emergência de novas modalidades". (THÉBAUD-MONY; DRUCK, 2007, p. 46). As autoras apontam que nos últimos quinze anos houve grande crescimento da terceirização/subcontratação em todas as direções, ocorrendo à expansão de novas modalidades. Dentre essas destacam como uma das principais, a que vem sendo utilizada tanto no setor público como no privado, a contratação de empresas individuais, que são em geral incentivadas pela lógica do empreendedorismo. Pautam-se pelo discurso da liberdade das empresas em se desobrigar dos compromissos de gestão do trabalho, dos encargos e direitos sociais

\footnotetext{
${ }^{5}$ Esta teoria auxilia o capitalismo em seus anseios, formando a mão de obra útil e necessária com os valores e atitudes que fomentam e ajudam o capitalismo em sua perpetuação e que na verdade apenas mantém a estrutura existente e aumenta as mazelas sociais.

${ }^{6}$ Corresponde à distribuição dos materiais na base da empreitada aos trabalhadores, para a manufatura em suas casas, por meio de subcontratadores e agentes de comissão.
} 
trabalhistas, forçando o trabalhador a constituir uma pessoa jurídica, registrando-a em seu nome, alterando assim sua personalidade jurídica. Esta situação transforma o assalariado em empresário, fazendo-o perder todos os direitos trabalhistas, pois o contrato agora se dá entre empresas, regido pelo direito comercial.

Essa "nova" forma de trabalho perpassa a ideia da existência da igualdade formal e da autonomia da vontade, sendo regulada pelo Direito Civil, coadunando-se com a ética do terceiro espírito do capitalismo, fomentador da autonomia, da liberdade, do individualismo, da mobilidade e do empreendedorismo. Na verdade, traz a concepção de biopolítica foucaultina para prática do poder de Estado.

As relações de poder utilizam o discurso jurídico para impor diversas formas de subjugação de dominação dos sujeitos, especialmente no que se refere à autonomia do pensamento, do próprio corpo e às relações de trabalho. Ora, ao se estudar as relações de trabalho postas se compreendem que a forma como as decisões, os regulamentos, os discursos ditos e não ditos e suas táticas, não emanam de um sujeito específico, mas de todas as estruturas que compõem esse campo social de onde deriva o poder regulador.

O poder atua na forma de melhor servir ao modo de produção capitalista, hoje representado pelo neoliberalismo, onde os corpos se encontram em constante disputa de forças. Nesta disputa tem prevalecido a constituição de um campo social do trabalho, pautado na exploração, na subcontratação e na precarização dos corpos dos trabalhadores.

Sendo o direito ao trabalho um direito social e, mais que isso, um direito humano fundamental cujo valor constitui a dignidade humana ao mesmo tempo em que é desdobramento da cidadania, sua desvalorização por quaisquer empreendimentos deve ser elidida e combatida. (LEITE, 2011). Tal assertiva corrobora a percepção de Santos (2003) ao considerar que:

Ao perder o estatuto político que detinha enquanto produto e produtor de cidadania, o trabalho fica reduzido à dor da existência, quer quando há - sob a forma de trabalho desgastante -, quer quando não há - sob a forma de desemprego, e não menos desgastante. É por isso que o trabalho, apesar de dominar cada vez mais as vidas das pessoas, está a desaparecer das referências éticas que dão suporte à autonomia e à autoestima dos sujeitos. (SANTOS, 2003, p.19). 
Essa é a razão pela qual a precariedade nas relações laborais ainda hoje se constitui como pauta de reivindicações de movimentos sociais que buscam impedir a naturalização de práticas que, embora legalmente amparadas, sejam desprotetivas, e também as que, a despeito de serem ilegais, são reiteradas no cotidiano do obreiro. Essa precariedade se aproxima daquilo que Foucault reitera em sua obra sobre o domínio dos corpos por regras que são manipuladas para formatar a vida humana em suas diversas dimensões.

Ao descrever o mundo do trabalho no contexto do que nominaram como "era da mundialização do capital”, Antunes e Alves (2004) caracterizam a classe trabalhadora no século XXI como ainda mais fragmentada, mais heterogênea e mais diversificada, uma sociedade que é também marcada por “[...] uma perda significativa de direitos e de sentidos, em sintonia com o caráter destrutivo do capital vigente." (ANTUNES; ALVES, p. 343). Essa perda de direitos em espaços diversos em tempos e momentos diferentes tem aproximações com o que Foucault concebe como biopolítica no sentido em que os corpos são moldados pelo poder em favor de algo para além de si.

Há, portanto, uma espécie de valorização às avessas que se manifesta no caráter destrutivo do descarte do trabalhador, uma vez que à medida que este se torna supérfluo, sua força de trabalho se torna mais frágil e suscetível à autoexploração:

Trata-se, portanto, de uma destrutividade que se expressa intensamente quando descarta, tornando ainda mais supérflua, parcela significativa da força mundial de trabalho, onde milhões encontram-se realizando trabalhos parciais, precarizados, na informalidade ou desempregados. Isso porque na eliminação/utilização dos resíduos da produção, o capital desemprega cada vez mais trabalho estável, substituindo-os por trabalhos precarizados, que se encontram em enorme expansão no mundo agrário, industrial e de serviços, bem como nas múltiplas interconexões existentes entre eles, como na agroindústria, nos serviços industriais ou na indústria de serviços. A eclosão generalizada do desemprego estrutural em escala transnacional é a expressão-limite mais aguda e trágica dessa destrutividade presente no mundo do trabalho. (ANTUNES, 2011, p. 408).

Sobre os impactos desses capitais globais nos direitos sociais, destaca-se a mercadorização do trabalho humano sob os auspícios de entidades internacionais que sustentam, sob a escusa de empréstimos que visam ao incentivo do desenvolvimento de políticas sociais a determinadas nações, a imposição de medidas que comprometem significativamente o avanço e o implemento de tais políticas, porém na base do 
discurso a conformação é a de que essas políticas são beneméritas à população.

Nessa perspectiva, há que se confrontar a influência exercida por entidades internacionais na política interna de países politicamente dependentes, isto é, de países caracterizados pela potencialidade mercantil e pelo inexpressivo desenvolvimento no campo das políticas de bem-estar social, nos quais a frágil consolidação de direitos civis e políticos contribui para a adesão de medidas de flexibilização das fronteiras nacionais e das políticas, sujeitando-as às ingerências de organizações que, por exercerem significativo domínio sob o capital estrangeiro, detêm o controle das influências nos investimentos transnacionais.

Em suma, considera-se que o (des)valor do trabalho humano na governamentalidade neoliberal se manifesta na desigualdade estrutural, como desdobramento de uma ordem global cujos impactos se dimensionam em prejuízo do trabalhador, produzindo relações caracterizadas por seu caráter flexível e desregulamentado.

A flexibilização trabalhista é "[...] adaptação das regras jurídicas a uma nova realidade, gerando um novo tipo de regulamentação" (SOUTO MAIOR, 2002, p.02), e vem sendo empregada no contexto de uma racionalidade governamental que se funda no neoliberalismo, como forma de desestabilização das relações trabalhistas, isto é, como forma de assegurar situações instáveis, inseguras, em afirmação da prevalência do capital sobre a força de trabalho.

Sob a ótica da governamentalidade neoliberal, os efeitos da articulação de tais instrumentos podem ser percebidos pela constatação de uma sociedade indexada na forma da empresa que reproduz nas relações laborais que se desenvolvem em sua conjuntura a mesma lógica concorrencial que a orienta. Nesse sentido, tomando por base a descrição de Souto Maior (2002) do que viria a caracterizar uma sociedade na qual a consciência econômica se sobrepõe à consciência social e, assim, produz e fomenta injustiças, se observa que [...] a sociedade que deveria se basear pelo pacto de solidariedade, se caracteriza, então, pela luta de todos contra todos, pelo salve-se quem puder: e que vença o melhor mais competente. Os custos de formação profissional preparam o jovem para este mundo da competição, e seja o que Deus quiser! (SOUTO MAIOR, 2002, p. 08).

Vê-se, portanto, se constituir um alicerce sobre o direito do trabalho orientado por fundamentos provenientes da lógica do mercado, viabilizando a legitimação da 
precariedade laboral na forma de práticas lesivas ao trabalhador, dentre as quais se situa a alteração da legislação trabalhista, e sob o manto do discurso da melhoria do país.

Por fim, Souza (2012) traz uma reflexão sobre o exercício do biopoder:

[...] é tão eficiente que se torna quase impossível pensar numa forma de resistência que de fato possa funcionar. Foucault fala do cuidado de si, de uma ética da bela existência; mas difundir uma ética de reflexão num mundo em que a moral comanda até mesmo as decisões políticas de saúde, ou em que a lei é a medida do que pode ser feito, não importando outras consequências, torna-se uma utopia diante das comprovações verificáveis da ciência e acatadas pela Justiça. Foucault propõe uma reflexão em torno da morte e da vida nas relações de poder. Se o biopoder é exercido tomando a vida como estratégia, a resistência só poderia ocorrer com a perda do medo da morte - medo que leva uma parte da população a desejar exterminar a outra parcela desta mesma população, como forma de garantir a própria sobrevivência, longevidade e - quem sabe - a possibilidade de se tornar eterna. (SOUZA, 2012, p. 54).

Logo, a biopolítica de Foucault está presente em toda a sociedade, permeando suas relações de poder e moldando os corpos por meio de discursos emanados do Estado que detém o poder regulador da vida.

\section{Considerações finais}

Foucault centrou seus esforços intelectuais na análise de um fenômeno social presente no mundo desde o advento da vida humana, o poder. Ele afirma que para ser o “proprietário" do poder, aquele que o exerce plenamente, necessariamente tem-se que possuir o saber, ou seja, aquele que detém conhecimento tem a habilidade e a capacidade de impor sua vontade e ideias sobre outros. O poder advém de uma relação interpessoal, onde um dos lados é o influenciador e o outro, o influenciado. Esse fenômeno igualmente é o responsável pela produção da verdade, visto que o poder é o responsável por alterar o modo como às pessoas enxergam o mundo.

Agora, em visão sobre a verdade, Foucault diz que ela jamais é absoluta, pois as visões de mundo adotadas pelas pessoas são moldadas por regras e condições que se alteram com o tempo. E, por fim, suas ideias caminham juntas, tanto com a crise das fundações totalizantes e absolutas quanto nas instituições sociais pós-modernas.

Sendo assim, um dos legados do renomado filósofo para o período da pós- 
modernidade é a relação indissociável de dependência entre saber, poder, verdade e discurso; um constrói e sustenta o outro, e o conceito de biopolítica deve ser compreendido em suas formulações históricas para que possamos entender essa relação, principalmente em suas vinculações com as relações de trabalho e educação.

\section{Referências}

ANTUNES, R.; ALVES, G. As mutações no mundo do trabalho na era da mundialização do capital. Educação \& Sociedade, Campinas, v. 25, n. 87, p. 335-351, maio/ago. 2004. Disponível em: <http://www.scielo.br/pdf/\%0D/es/v25 n87/21460.pdf>. Acesso: 29 jul 2019.

ARAUJO, A. P. de. Para ler A Ordem do discurso de Michel Foucault. Disponível em: <https://goo.gle/Jnpl.kU >. Acesso: 22 jul 2019.

AYUB, J. P. Introdução à analítica do poder de Michel Foucault. São Paulo: Intermeios, 2014.

BERT, J. Pensar com Michel Foucault. São Paulo: Parábola, 2013.

CASTRO, E. Lecturas foucaulteanas. Una historia conceptual de la biopolítica. La Plata: Unipe Editorial Universitaria, 2011. Disponível em: <https://pt.scribd.com/document/345628116/Castro-Edgardo-2011-LecturasFoucaulteanas>. Acesso: 22 jul 2019.

- O Governo da Vida. Una historia conceptual de la biopolítica. La Plata: Unipe Editorial Universitaria, 2011. p. 27-51. Disponível em: <https://revistas.pucsp.br/ecopolitica/article/viewFile/11391/8300>. Acesso: 24 jul 2019.

CANDEIAS, A. Modelos alternativos de escola na transição do século XIX para o século XX. In: SOUZA, C. P., CATANI, BARBARA, D. (org.): Práticas Educativas, culturais, escolares a profissão docente. São Paulo: Editora Escritoras Editoras, 131-142p.

ESPOSITO, R. Bios: biopolítica e filosofia. Lisboa: Edições 70, 2010. Disponível em: <https://laboratoriodesensibilidades.files.wordpress.com/2018/09/esposito-robertobios-biopolicc81tica-e-filosofia-com-leitura-binocularizada.pdf>. Acesso: 18 jul 2019. FOUCAULT, M. Vigiar e Punir. 3. ed.. Rio de Janeiro: Vozes, 1987.

Sobre as maneiras de escrever a história. In: MOTTA, M. B. da (org.) Foucault: arqueologia das ciências e história dos sistemas de pensamento. Ditos e Escritos II. Rio de Janeiro: Forense Universitária, 2000.

. Conferência 1 In: A Verdade e as Formas Jurídicas. Trad. Roberto Cabral de Melo Machado e Eduardo Jardim Morais. Rio de Janeiro. NAU Editora, 2003.

A ordem do discurso. Trad. Graciano Barbachan (data da digitalização: 2004). Coletivo Sabotagem. 1996.

- Segurança, Território, População: curso dado no Collège de France (19771978). São Paulo: Martins Fontes, 2008.

Nascimento da biopolítica: curso dado no Collège de France (1978-1979).

São Paulo: Martins Fontes, 2008.

. Em defesa da sociedade: curso no Collège de France (1975-1976). 2. ed.

São Paulo: WMF Martins Fontes, 2010.

História da sexualidade I: a vontade de saber. Rio de Janeiro: Edições 
Graal, 2012.

GUTTING, G.; OKSALA, J. Michel Foucault. The Stanford Encyclopedia of Philosophy (Spring 2019 Edition). Edward N. Zalta: 2019. Disponível em <<https://plato.stanford.edu/archives/spr2019/entries/foucault/>>. Acesso: 29 jul 2019.

HARDT, M.; NEGRI, A. Império. Rio de Janeiro: Record, 2004.

HARDT, M.; NEGRI, A. Multidão: guerra e democracia na era do Império. São Paulo: Record, 2005.

LEITE, C. H. B. Direitos humanos. 2. ed. Rio de Janeiro: Lumen Juris, 2011.

REVEL, J. Nas origens do biopolítico: de Vigiar e Punir ao pensamento da atualidade. In. GONDRA, José; KOHAN, Walter Omar. Foucault 80 anos. Belo Horizonte: Autêntica, 2006, p. 51-62.

SANTOS, B. de S. Poderá o direito ser emancipatório? Revista Crítica de Ciências

Sociais, n. 65, p. 3-76, maio 2003. Disponível em: <http://www.boaventuradesousasantos.pt/media/pdfs/podera_o_direito_ser_emanci patorio_RCCS65.PDF>. Acesso: 29 jul 2019.

SOUTO MAIOR, J. L. A Fúria. Revista LTR, São Paulo, v. 66, n. 11, p. 1287-1309, 2002.

Disponível

em:

<https://www.jorgesoutomaior.com/uploads/5/3/9/1/53916439/a_furia.pdf>.

Acesso: 29 jul 2019.

SOUZA, K. M. Discurso de biopolítica na sociedade de controle. In: Produção de identidades e processos de subjetivação em práticas discursivas. Israma Tasso, Pedro Navarro (org). Maringá: Eduem, 2012. pp. 41-55. ISBN 978-85-7628-583-0. Available from SciELO Books. Disponível em: <http://books.scielo.org/id/hzj5q/pdf/tasso-9788576285830-03.pdf>. Acesso: 22 jul 2019.

TRÉBAUD-MONY, A.; DRUCK, G. (2007). Terceirização: a erosão dos direitos dos trabalhadores na França e no Brasil. In G. Druck \& T. Franco (Orgs.), A perda da razão social do trabalho: terceirização e precarização. São Paulo: Boitempo.

VEIGA-NETO, A. (org.). Imagens de Foucault e Deleuze: ressonâncias nietzschianas. Rio de Janeiro: DP\&A, 2002, p. 13-34.

Foucault \& a Educação. 3. ed. Belo Horizonte: Autêntica, 2011. 